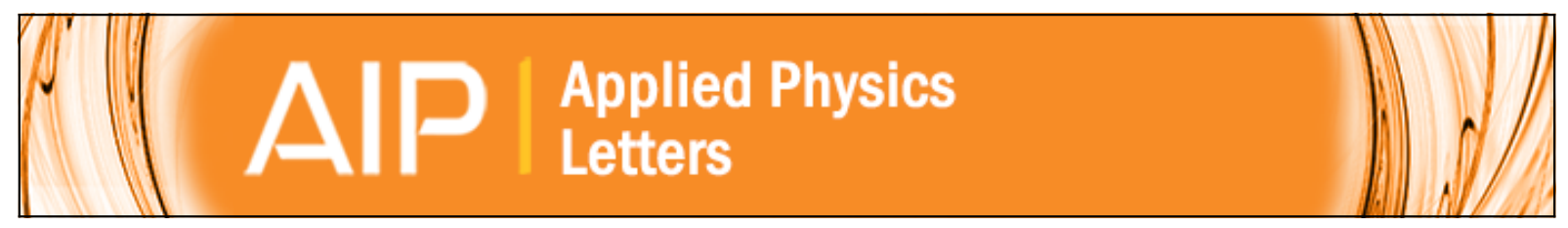

\title{
Gettering of Pd to implantation-induced nanocavities in $\mathrm{Si}$
}

D. A. Brett, G. de M. Azevedo, D. J. Llewellyn, and M. C. Ridgway

Citation: Applied Physics Letters 83, 946 (2003); doi: 10.1063/1.1597424

View online: http://dx.doi.org/10.1063/1.1597424

View Table of Contents: http://scitation.aip.org/content/aip/journal/apl/83/5?ver=pdfcov

Published by the AIP Publishing

\section{Articles you may be interested in}

Effects of surface oxide layer on nanocavity formation and silver gettering in hydrogen ion implanted silicon J. Appl. Phys. 114, 023502 (2013); 10.1063/1.4812736

Trapping of $\mathrm{Pd}, \mathrm{Au}$, and $\mathrm{Cu}$ by implantation-induced nanocavities and dislocations in $\mathrm{Si}$ Appl. Phys. Lett. 88, 222107 (2006); 10.1063/1.2208382

Gettering of copper in silicon at half of the projected ion range induced by helium implantation J. Appl. Phys. 91, 69 (2002); 10.1063/1.1418005

Copper gettering at half the projected ion range induced by low-energy channeling He implantation into silicon Appl. Phys. Lett. 77, 972 (2000); 10.1063/1.1289062

The role of oxygen on the stability of gettering of metals to cavities in silicon Appl. Phys. Lett. 75, 2424 (1999); 10.1063/1.125035

\section{Model PS-100}

Tabletop Cryogenic Probe Station

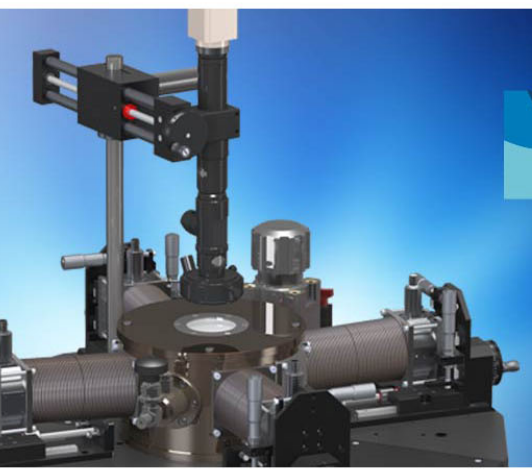

\section{Lake Shore} CRYOTRONICS

An affordable solution for a wide range of research 


\title{
Gettering of Pd to implantation-induced nanocavities in Si
}

\author{
D. A. Brett, ${ }^{\text {a) }}$ G. de M. Azevedo, D. J. Llewellyn, and M. C. Ridgway \\ Department of Electronic Materials Engineering, Research School of Physical Sciences and Engineering, \\ Australian National University, Canberra ACT 0200 Australia
}

(Received 2 May 2003; accepted 12 June 2003)

\begin{abstract}
The gettering of $\mathrm{Pd}$ to nanocavities in $\mathrm{Si}$ for implantation doses ranging from $5 \times 10^{13}$ to 1 $\times 10^{15} \mathrm{~cm}^{-2}$ and annealing temperatures ranging from 750 to $1050{ }^{\circ} \mathrm{C}$ was investigated using Rutherford backscattering and cross-sectional transmission electron microscopy. For a given annealing temperature, the gettering efficiency increased as the dose decreased. For a given dose, maximum gettering efficiency was achieved at the intermediate temperatures studied. Competition between silicide formation and nanocavity gettering limited gettering efficiency. (c) 2003 American Institute of Physics. [DOI: 10.1063/1.1597424]
\end{abstract}

Transition metal contamination can inject undesired deep levels, reduce minority carrier lifetime, and impede the proper functioning of $\mathrm{Si}$ devices. ${ }^{1}$ However, nanocavities formed in $\mathrm{Si}$ by $\mathrm{H}$ or $\mathrm{He}$ implantation and subsequent annealing are effective in gettering a number of transition metals, including $\mathrm{Ni},{ }^{2} \mathrm{Cu},{ }^{3} \mathrm{Ag},{ }^{4} \mathrm{Pt},{ }^{4}$ and $\mathrm{Au} .{ }^{5}$ It is the dangling bonds on the inner surface of such nanocavities that form attractive trapping or gettering sites for these metallic impurities. ${ }^{6}$ Nanocavities can trap metal contaminants outside the device active region, yet may be formed on the device side of the wafer, making them potentially useful for proximity gettering. In this letter, we investigate the gettering of Pd to implantation-induced nanocavities in $\mathrm{Si}$. This report on the interaction between $\mathrm{Pd}$ and nanocavities is timely, given that this transition metal has potential applications in device manufacture, for instance as a component of an interconnect alloy. ${ }^{7}$ By investigating a range of doses and annealing temperatures, we explore the relationship between $\mathrm{Pd}$ gettering efficiency and the processing parameters.

A single nanocavity band was formed in (100) Czochralski Si wafers by room temperature implantation of $30 \mathrm{keV}$ $\mathrm{H}^{-}$ions (with a projected range of $\left.\sim 380 \mathrm{~nm}\right)^{8}$ to a dose of $3 \times 10^{16} \mathrm{~cm}^{-2}$. This was followed by annealing for $1 \mathrm{~h}$ at $850^{\circ} \mathrm{C}$ under flowing $\mathrm{Ar}$ to induce nanocavity formation. The nanocavities thus produced had an average diameter of $\sim 10 \mathrm{~nm}$ and a surface area corresponding to an areal dose of $1 \times 10^{14} \mathrm{~cm}^{-2}$. $^{3} \mathrm{Pd}$ was then introduced into the samples by room temperature implantation of $235 \mathrm{keV} \mathrm{Pd}^{+}$ions (with a projected range of $\sim 110 \mathrm{~nm}$ ) to doses ranging from 5 $\times 10^{13}$ to $1 \times 10^{15} \mathrm{~cm}^{-2}$. This implant was followed by an anneal for $1 \mathrm{~h}$ under flowing $\mathrm{Ar}$ at temperatures ranging from 750 to $1050{ }^{\circ} \mathrm{C}$, to enable $\mathrm{Pd}$ diffusion and induce gettering. The samples were then analyzed by random-orientation $\mathrm{Ru}-$ therford backscattering (RBS) with $1.6 \mathrm{MeV} \mathrm{He}^{+}$ions and a scattering angle of $168^{\circ}$. Cross-sectional transmission electron microscopy (XTEM) analysis was performed on selected samples using a Phillips CM-300 microscope operating at $300 \mathrm{kV}$.

Figure 1 shows RBS spectra of a $5 \times 10^{14} \mathrm{Pd} \mathrm{cm}^{-2}$ im-

\footnotetext{
a) Author to whom correspondence should be addressed; electronic mail: dab109@rsphysse.anu.edu.au
}

plant before and after annealing at $950^{\circ} \mathrm{C}$. Before annealing, the implanted Pd is centered at a depth of $\sim 120 \mathrm{~nm}$, consistent with the range predicted by SRIM 2000. Subsequent to annealing, the Pd has clearly redistributed from the implant region to a depth of $\sim 390 \mathrm{~nm}$. The fraction gettered under these conditions is $(51 \pm 4) \%$. XTEM confirmed the presence of a nanocavity band centered at a depth of $\sim 385 \mathrm{~nm}$, corresponding with the peak of the $\mathrm{H}$ implant distribution predicted by SRIM 2000, and the depth at which RBS analysis indicated the presence of gettered Pd. This was consistent with previous work that showed nanocavities form at the peak of the implant distribution. ${ }^{6}$ The micrograph of Fig. 2 is taken from a $1 \times 10^{15} \mathrm{Pd} \mathrm{cm}^{-2}$ implant annealed at $950{ }^{\circ} \mathrm{C}$ for $1 \mathrm{~h}$ and shows at least two nanocavities with evidence of crystalline precipitates. The moiré patterns were consistent with PdSi, the most Si-rich silicide phase observed following thermal annealing of $\mathrm{Pd}$ layers on $\mathrm{Si}$ at atmospheric pressure. ${ }^{9}$ Nonetheless, for the experimental uncertainty associated with the moire fringe analysis, $\mathrm{Pd}_{2} \mathrm{Si}$ could not be excluded as a possibility.

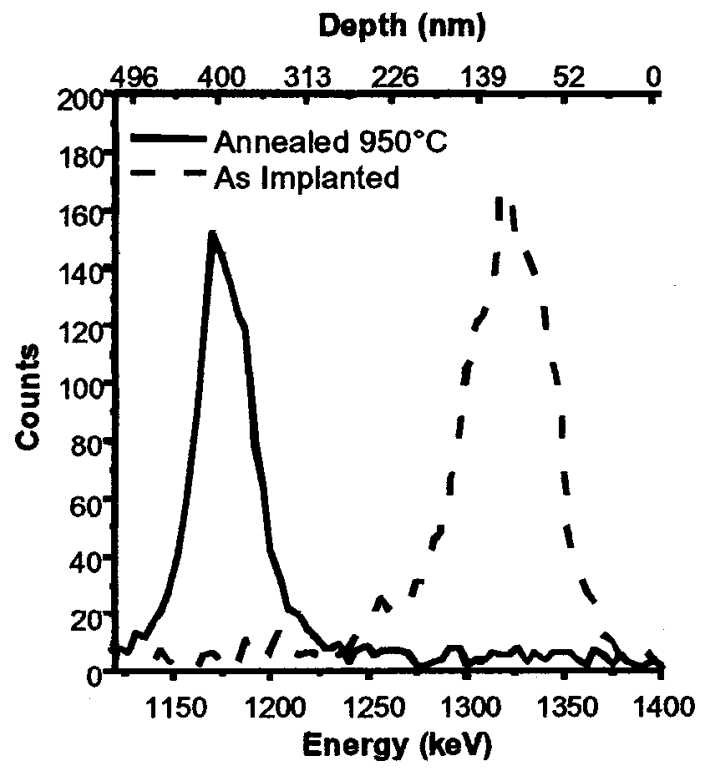

FIG. 1. RBS spectra of backscattered ion counts as functions of backscattered ion energy and depth below the surface of a $235 \mathrm{keV}, 5$ $\times 10^{14} \mathrm{Pd} \mathrm{cm}^{-2}$ implanted sample both before and after annealing at $950{ }^{\circ} \mathrm{C}$ for $1 \mathrm{~h}$. 


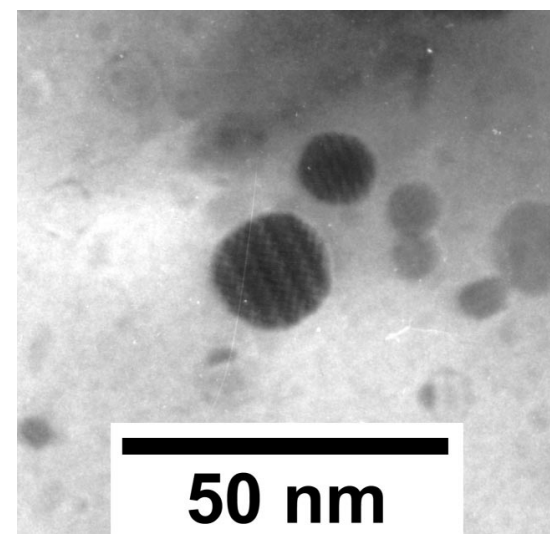

FIG. 2. Micrograph of a $235 \mathrm{keV} 1 \times 10^{15} \mathrm{Pd} \mathrm{cm}^{-2}$ implanted sample following annealing at $950{ }^{\circ} \mathrm{C}$ for $1 \mathrm{~h}$. Note the nanocavities containing moiré fringes at the center of the image.

In Fig. 3 the gettering efficiencies as functions of $\mathrm{Pd}$ dose and annealing temperature are shown. For all doses, gettering efficiency is a maximum at an intermediate annealing temperature: the gettering efficiency is lower for annealing at 750 and $1050{ }^{\circ} \mathrm{C}$ and higher for annealing at 850 and $950{ }^{\circ} \mathrm{C}$. The optimum temperature for maximum gettering efficiency increases as the $\mathrm{Pd}$ dose increases. At $750^{\circ} \mathrm{C}, \mathrm{Pd}$ was detected at a depth of $\sim 90 \mathrm{~nm}$ for all doses, up to $\sim 98 \%$ of the total in the case of the $1 \times 10^{15} \mathrm{~cm}^{-2}$ implant, despite a diffusion length of $\sim 2 \mathrm{~mm}$ for $\mathrm{Pd}$ at this temperature and annealing time. ${ }^{10}$ This Pd was closer to the surface than originally implanted, suggesting Pd segregated during the solid-phase epitaxial regrowth (SPEG) of the Si layer amorphized by the Pd implant. For the lowest dose, amorphization was incomplete and a lesser fraction of Pd was detected at $\sim 90 \mathrm{~nm}$. To better understand the accumulation of $\mathrm{Pd}$ at such depths, selected samples were implanted at $300^{\circ} \mathrm{C}$. The gettering efficiency was improved by implanting $\mathrm{Pd}$ at $300^{\circ} \mathrm{C}$. This suggests segregated $\mathrm{Pd}$ may form a silicide during or subsequent to SPEG, and this silicide phase must be dissolved to enable gettering at the nanocavities. This difficulty in relocating Pd from the implant region to the nanocavities

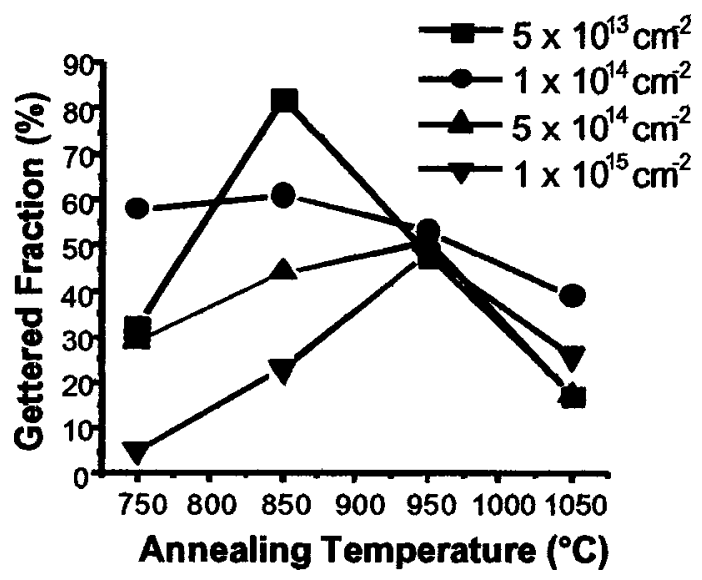

FIG. 3. RBS data showing the gettering efficiency as a function of Pd dose and annealing temperature. Values are accurate to within \pm 26 for 5 $\times 10^{13} \mathrm{Pd} \mathrm{cm}^{-2}, \quad \pm 14$ for $1 \times 10^{14} \mathrm{Pd} \mathrm{cm}^{-2}$, and \pm 4 for both 5 $\times 10^{14} \mathrm{Pd} \mathrm{cm}^{-2}$ and $1 \times 10^{15} \mathrm{Pd} \mathrm{cm}^{-2}$. was not unexpected-similar observations have been reported for $\mathrm{Ni}^{2}$ and $\mathrm{Pt}^{4}{ }^{4}$ Given $\mathrm{Pd}, \mathrm{Ni}$, and Pt readily form silicides, silicide formation competes with nanocavity gettering. This is in contrast to other metals, such as $\mathrm{Cu}$ or $\mathrm{Au}$, which do not readily form silicides, and exhibit much higher gettering efficiencies. ${ }^{10,11}$ At the annealing temperature of $850^{\circ} \mathrm{C}$, only the RBS spectrum of the $1 \times 10^{15} \mathrm{~cm}^{-2}$ implant showed detectable amounts of Pd near the surface $(\sim 45 \mathrm{~nm})$, and none could be detected at $950^{\circ} \mathrm{C}$. We attribute such results to increased diffusivity, solubility and silicide dissolution. At $1050{ }^{\circ} \mathrm{C}$, the gettering efficiency is lower for all doses and Pd is broadly distributed between the cavity band and the surface. This suggests Pd may have redistributed away from the nanocavity band at this temperature. Possible causes for such behavior at this temperature include gettering of $\mathrm{O}$ from within Czochralski Si with subsequent ejection of previously trapped metal, ${ }^{12}$ nanocavity instability, ${ }^{13}$ and metal detrapping from nanocavity walls due to thermal excitation. ${ }^{14}$ In general, the amount of Pd not located in the nanocavities or in the implant region was below the calculated solubility of $\mathrm{Pd}$ at the annealing temperatures, ${ }^{9,15}$ thus indicating that nanocavities are an efficient sink for Pd.

In conclusion, we have demonstrated that nanocavities in Si can effectively getter Pd. The efficiency of this process was greatest at intermediate annealing temperatures and increased as the Pd dose decreased. The gettering efficiency of the nanocavities is adversely affected by Pd silicide formation. These results will aid in further studies of the interaction between transition metals and nanocavities in Si.

The authors thank the Australian Research Council for their financial support. G.deM.A. acknowledges the Brazilian agency CNPq (Conselho Nacional de Desenvolvimento Científico e Tecnológico) for a postdoctoral fellowship.

${ }^{1}$ K. Graff, Mater. Sci. Eng., B 4, 63 (1989).

${ }^{2}$ B. Mohadjeri, J. S. Williams, and J. Wong-Leung, Appl. Phys. Lett. 66, 1889 (1995).

${ }^{3}$ J. Wong-Leung, C. E. Ascheron, M. Petravic, R. G. Elliman, and J. S. Williams, Appl. Phys. Lett. 66, 1231 (1995).

${ }^{4}$ A. Kinomura, J. S. Williams, J. Wong-Leung, and M. Petravic, Nucl. Instrum. Methods Phys. Res. B 127/128, 297 (1997).

${ }^{5}$ J. Wong-Leung, J. S. Williams, and E. Nygren, Nucl. Instrum. Methods Phys. Res. B 106, 424 (1995).

${ }^{6}$ J. S. Williams, M. C. Ridgway, M. C. Conway, J. Wong-Leung, X. Zhu, M. Petravic, F. Fortuna, M.-O. Ruault, H. Bernas, A. Kinomura, Y. Nakano, and Y. Hayashi, Nucl. Instrum. Methods Phys. Res. B 178, 33 (2001).

${ }^{7}$ A. G. Dirks, R. A. Augur, and A. E. M. de Veirman, Thin Solid Films 246, 164 (1994).

${ }^{8}$ J. F. Ziegler, J. P. Biersack, and U. Littmark, The Stopping and Range of Ions in Solids (Pergamon, New York, 1985).

${ }^{9}$ W. Schröter and M. Seibt, in Properties of Crystalline Silicon, edited by R. Hull (INSPEC, London, 1998), No. 20, pp. 543-560.

${ }^{10} \mathrm{~K}$. Graff, Metal Impurities in Silicon-Device Fabrication, 2nd ed. (Springer, Berlin, 2000).

${ }^{11}$ J. Wong-Leung, J. S. Williams, A. Kinomura, Y. Nakano, Y. Hayashi, and D. J. Eaglesham, Phys. Rev. B 59, 7990 (1999).

${ }^{12}$ J. S. Williams, M. Conway, J. Wong-Leung, P. N. K. Deenapanray, M. Petravic, R. A. Brown, D. J. Eaglesham, and D. C. Jacobson, Appl. Phys. Lett. 75, 2424 (1999).

${ }^{13}$ X. Zhu, J. S. Williams, D. J. Llewellyn, and J. C. McCallum, Appl. Phys. Lett. 74, 2313 (1999).

${ }^{14}$ V. Raineri, P. G. Fallica, G. Percolla, A. Battaglia, M. Barbagallo, and S. U. Campisano, J. Appl. Phys. 78, 3727 (1995).

${ }^{15}$ K. Graff, H.-A. Hefner, and H. Pieper, Mater. Res. Soc. Symp. Proc. 36, 19 (1985). 